\title{
The laws of social reproduction: a lesson in appropriation
}

\author{
PrabHa KotisWaran ${ }^{1}$
}

Dickson Poon School of Law, King's College London

\begin{abstract}
$\underline{\text { Abstract }}$
This article offers insights into the law's appropriation of women's reproductive labour, namely, the intimate labours that they typically carry out in the context of marriage to biologically, socially, emotionally and culturally reproduce members of the household by offering a range of goods and services. Feminist legal scholars have long demonstrated the law's failure to recognise, much less value, such reproductive labour. Where the law does recognise such labour, feminists argue that it is largely within the parameters of the institution of heterosexual marriage to the exclusion of other organisational forms. The article extends this line of feminist legal critique to reveal feminists' own reluctance within the debates on social reproduction to recognise the reproductive labour performed by women outside the family and explicitly for the market. Through a cross-sectoral comparison of the law's regulation of three such sectors of women's abject labour, namely, sex work, bar-dancing and commercial surrogacy, the article demonstrates how, despite their regulation through criminal law, licensing law and contract law, there are several structural similarities in the political economies of these sectors. Consequently, any change in the rule network pertaining to any one sector of women's reproductive labour affects women in that sector but also in other sectors. The article argues that it is only through an examination of the deep interconnectedness between sectors of women's reproductive labour that feminists can assess whether an alternative regulatory matrix would further women's claims to economic justice.
\end{abstract}

\section{Introduction}

$\mathrm{T}$ 2011 film Made in India documents the story of Lisa and Brian, a couple from Austin, Texas, who, in their desperation to complete their family, arrive in Mumbai and avail themselves of the services of a surrogate, Aasia. Aasia, a Muslim woman living in the slums of Mumbai with her three young children, is recruited by her sister-in-law to carry a baby for Lisa. Interestingly, Lisa is a nurse who has to sell her house in Texas to be able to afford surrogacy in India. Meanwhile, Aasia's husband, a car mechanic, has seen his earnings dwindle along with the informal car-repair economy. The documentary follows the arc of emotions from the initial euphoria and gratitude of the commissioning parents and the surrogate to the eventual souring of their relations and haggling over the price for the surrogate's services for delivering twins. Even as Aasia returns to the fertility clinic not long after Lisa and Brian have left, to try her hand at surrogacy again, I realised that Aasia's background as a poorly educated domestic maid was not altogether different from the many women I had encountered while

1 prabha.kotiswaran@kcl.ac.uk. Many thanks to Amanda Perry-Kessaris for her excellent feedback. 
conducting an ethnographic study of sex work in Sonagachi, the largest red-light area in Kolkata. Almost two-thirds of the women there had been married before, many with small children, when they started selling sex. They often came into sex work from other sectors of the informal economy such as domestic work and construction work. Meanwhile, in the very same red-light areas where Mumbai's sex workers worked from, lived the city's bar dancers who shared in the stigma of the labour they performed by night. Yet surrogates, sex workers and bar dancers generally have one thing in common - an income that far exceeds what women with their education and skills could command in the informal economy. In this article, I ask how feminists might theorise the intimate labours of social reproduction typically carried out within the home that these various women perform for the market? Further, how does the law shape their choices to enter these abject labour markets, their prospects for work in these markets and exit from them?

In so doing, I revisit law's appropriation of women's labour, in particular, reproductive labour. By reproductive labour, I mean the labour involved in social reproduction, namely, 'biological reproduction; unpaid production in the home (both goods and services); social provisioning (. . . voluntary work directed at meeting needs in the community); the reproduction of culture and ideology; and the provision of sexual, emotional and affective services (such as are required to maintain family and intimate relationships)', ${ }^{2}$ all of which are performed predominantly by women, typically within the institutional context of marriage. Successive waves of feminist scholarship have highlighted the reproductive labour that women perform. Demands for the recognition of this labour have ranged from radical proposals, such as wages for housework in the 1970s, to more recent attempts at the equitable distribution of marital property upon the termination of a marriage to a rearrangement of responsibilities for care between men and women when both participate in the paid labour market. ${ }^{3}$

Social reproduction under neoliberal conditions of globalisation has, however, dramatically shifted the parameters of these debates. Decisive trends, according to scholars, include women's increased employment in the West, a larger aging population and declining social welfare, which have resulted in the homemaker/breadwinner 'family wage' model being replaced by a 'dual earner model' that seeks to accommodate global competitive pressures for flexible labour. ${ }^{4}$ Confronted with the crises that the global economy and welfare states are thrown into, feminists point to how women are not only increasingly called upon to perform paid work in and for transnational markets, but that they also face increased burdens of social reproduction. This may be ameliorated to some extent by the vast inflow of female migrant workers from the developing world, particularly for domestic work and child-care. ${ }^{5}$ Yet, as states are driven by neoliberal thinking to address the 'care deficit', ${ }^{6}$ feminist scholars point out that 'the gap between the outflows - domestic, affective and reproductive labour - and the inflows - medical care, income earned and leisure time

2 C Hoskyns and S Rai, 'Recasting the Global Political Economy: Counting Women's Unpaid Work' (2007) 12(3) New Political Economy 297-317, 300.

3 For a debate amongst legal feminists on whether the law should support women's increased paid work in the labour market or compensate them for the unpaid work they perform at home, see the 2000-2001 special issue of the Chicago-Kent Law Review.

4 J Conaghan, 'Introduction' (2007) 58(4) Northern Ireland Legal Quarterly 248-49 Special Issue: Legal Constructions of Unpaid Caregiving.

5 H Shamir, 'Between Home and Work: Assessing the Distributive Effects of Employment Law in Markets of Care' (2009) 30 Berkeley Journal of Employment and Labor Law 404, 439-40.

6 Conaghan (n 4) 247. 
- falls below a threshold of biological, financial and affective sustainability' ${ }^{7}$ which has resulted in the depletion of social reproduction. ${ }^{8}$

The challenges facing the provision of social reproduction are significantly different in the developing world. For one, the institutions constituting what Razavi calls the 'care diamond', which meet the needs of social reproduction, namely, the market, family, state and community, ${ }^{9}$ are configured in fundamentally varied ways when compared with the West. In a country like India, for instance, the welfare state is at best minimalist, constituting a 'residual welfare regime'. ${ }^{10}$ Urban women's participation in the workforce is abysmally low at 16 per cent resulting in the family being the privileged site of care work. Where women's work has been commodified; it is in sectors like teaching or paid domestic work, which accommodate unpaid reproductive labour more easily. ${ }^{11}$ The institutional parameters within which the political economy of reproductive labour is nestled and the regulatory impulses that govern it are thus driven by what Palriwala and Neetha term 'gendered familialism'. ${ }^{12}$ In other words, care is a familial and female responsibility and work in the market devalues and diminishes the dimensions of care. ${ }^{13}$ Paradoxically, however, feminists also delineate the patriarchal reorganisation of reproduction ${ }^{14}$ whereby sex selection has increasingly become a technique used to facilitate female foeticide in the post-conception, prenatal moment rather than killing women through dowry harassment or prematurely later in their life cycles. The resultant lop-sided sex ratio of $914: 1000^{15}$ as reported by the 2011 Indian census has fuelled the trafficking of women for social reproduction. ${ }^{16}$

Like their feminist counterparts in other disciplines, feminist legal scholars have on many occasions engaged with the law's regulation of women's reproductive labour. They have, in particular, demonstrated the central role of the law in producing and entrenching the invisibility of women's reproductive labour. As I will show, the feminist legal theorising of social reproduction reveals the sheer contingency of the regulatory matrix governing the family and unpaid housework. One can discern two strains of theorising here. Much of the early, path-breaking work on the law's regulation, and, indeed, appropriation of women's reproductive labour, dealt with the lack of legal recognition of women's reproductive labour as valuable. In this vein was Katherine Silbaugh's writing on the significance of legal rules ranging from family law through to tort law, welfare law, bankruptcy law, tax law and labour law that consistently failed to value women's housework. In the process of revealing that these rules did not recognise women's housework, but could have, Silbaugh's work also showed that no default legal regime

7 S Rai, C Hoskyns and D Thomas, 'Depletion: The Costs of Unpaid Domestic Work' <www.e-ir.info/ 2012/03/19/depletion-the-costs-of-unpaid-domestic-work/>.

8 Ibid.

9 S Razavi, "The Political and Social Economy of Care in a Development Context: Conceptual Issues, Research Questions and Policy Options' (Gender and Development Programme, Paper No 3, United Nations Research Institute for Social Development, Geneva 2007) 20.

10 R Palriwala and N Neetha, 'Stratified Familialism: The Care Regime in India through the Lens of Childcare' (2011) 42(4) Development and Change 1049-78, 1050.

11 Ibid 1054.

12 Ibid 1049.

13 Ibid.

14 K Sangari, 'Settled Alibis and Emerging Contradictions: Sex Selection, Dowry and Domestic Violence' (2012) 47(34) Economic and Political Weekly 39-48.

15 'India's Skewed Sex Ratios: Gendercide Stings' (Banyan Asia 18 December 2012) $<$ www.economist.com/blogs/banyan/2012/12/indias-skewed-sex-ratios>.

16 N Antelava, 'The Girls Stolen from the Streets of India' (BBC News Magazine 9 January 2013) <www.bbc.co.uk/news/magazine-20938125>. 
governing a certain sector of women's work at any given point in time is necessary in any way. In other words, legal categories are contingent. Thus, we may currently default to using family law for recognising women's reproductive labour, although labour law might just as well have mandated wages for housewives. Indeed, feminist lawyers continue to delineate how unpaid care-giving is regulated by laws as disparate as property law, family law, labour law, tort law, European Union and international law. ${ }^{17}$ It is this contingent legal categorisation of women's labour that both itself amounts to and further enables the patriarchal appropriation of women's labour. Meanwhile, some legal feminists reached into the depths of Carol Gilligan's work on difference to articulate a normative view of unpaid reproductive labour or care work, ${ }^{18}$ which was reflected in a range of legal proposals, ${ }^{19}$ thus bolstering feminist claims to the recognition of social reproduction.

Other legal feminists have increasingly focused on theorising care in terms of redistribution, ${ }^{20}$ especially intra-gender redistribution or the effects of recognising the reproductive labour of wives for other women. ${ }^{21}$ Thus, Mary Ann Case asks if increased employer responsibility for children does not in fact prejudice the interests of working women like herself who do not have children and does not, indeed, ultimately promote the interests of married working men who have stay-at-home wives to perform reproductive labour for the family. ${ }^{22}$ Feminist legal realists like Halley, Rittich and Shamir continue in this vein. Their starting point is to highlight the significance of background legal rules, which influence the bargaining power of a social actor in any given situation. Thus, Halley and Rittich have argued against the exceptionalist legal treatment of the family through family law (FL), back-grounding legal rules in the process into several categories ranging from FL1, the subject matter of family law textbooks, to FL2 (tax, immigration, bankruptcy laws), FL3 (tenancy law, employment rules, labour laws) and FL4 (incorporating norms around the household). ${ }^{23}$ The exceptional status of the family as a legal category thus performs concrete distributional work. Similarly, Shamir assesses the distributive consequences of accommodations structured within employment law for working families, which were meant to recognise care responsibilities but can in fact have unpredictable effects that consolidate and entrench class and gender disparities. Thus, Shamir's analysis shows that the ability of a worker to take unpaid leave to care for oneself, a child or a

17 Conaghan (n 4) 245.

18 See the discussion of care feminists in P Tsoukala, 'Gary Becker, Legal Feminism, and the Costs of Moralizing Care’ (2007) 16 Columbia Journal of Gender and Law 387-8.

19 M Ertman, 'Commercializing Marriage: A Proposal for Valuing Women's Work through Premarital Security Agreements' (1998) 77 Texas Law Review 17-112.

20 I draw on Nancy Fraser's use of these terms in her influential book Justice Interruptus: Critical Reflections on the Postsocialist Condition (Routledge 1997). I do not make sharp distinctions here between recognition and redistribution, much less, their attenuated mapping onto a culture/economy distinction. Demands for recognition might well also incorporate demands for redistribution, as in the case of sex workers. Conversely, what might appear to be demands for redistribution (such as, say, labour rights for domestic workers) could well translate into demands for recognition and dignity and, indeed, disassociation from domestic work. See S Chigateri, 'Articulations of Injustice and the Recognition - Redistribution Debate: Locating Caste, Class and Gender in Paid Domestic Work in India' (2007) (1) Law, Social Justice and Global Development Journal $<$ http://go.warwick.ac.uk/lgd/2007_1/chigateri>.

21 J Halley and K Rittich, 'Critical Directions in Comparative Family Law: Genealogies and Contemporary Studies of Family Law Exceptionalism - Introduction to the Special Issue on Comparative Family Law' (2010) 58(4) American Journal of Comparative Law 753; M A Case, 'How High the Apple Pie? A Few Troubling Questions about Where, Why, and How the Burden of Care for Children Should be Shifted' (2001) 76 Chicago-Kent Law Review 1753-86; K Franke, 'Theorizing Yes: An Essay on Feminism, Law, and Desire' (2001) 101 Columbia Law Review 181.

22 Case (n 21) 1756.

23 Halley and Rittich (n 21). 
specified family member who is seriously sick under the US Family and Medical Leave Act 1993 might be ultimately used only by working women rather than their husbands due to the gender wage gap. ${ }^{24}$ Alternatively, the fact that such leave is unpaid means that, in the absence of any other leave entitlement, only middle-class workers can avail themselves of this optional benefit. ${ }^{25}$ The legal analysis here is attentive to the broader institutional framework, such as the orientation of a particular welfare state, as well as the interaction between conventional employment law applicable to the formal economy and the lack of such protections for the secondary labour market of migrant care workers who support working parents.

A further line of feminist legal critique relates to the narrow parameters of the law's recognition of female reproductive labour, normalising in effect the institution of heterosexual marriage to the exclusion of other organisational forms for the provision of social reproduction. ${ }^{26}$ Barlow goes so far as to suggest the existence of a sliding scale of value, ${ }^{27}$ wherein a high value is placed on non-financial contributions to a marriage, which is not available within cohabitation law. ${ }^{28}$ Even less value is accorded in the context of noncouple care-giving relationships or state-dependent single parenthood where paid work is considered to be the carer's primary goal and reproductive labour becomes non-existent at best. Similarly, recognition of the reproductive labour of families formed by lesbians, gays, bisexuals and transsexuals is premised on their approximation of the heterosexual marriage model requiring: 'two parents (no more), cohabiting in a monogamous, long-standing relationship, acting as one economic unit with the associated assumptions around financial dependency, and involved in a romantically defined sexual relationship'. ${ }^{29}$

Feminist endeavours to convince states and increasingly international institutions to recognise women's reproductive labour have met with little success. As feminist economists and development theorists look to successful campaigns elsewhere in trying to get the UN to redraw the 'production boundary', 30 feminist lawyers have had to be content with family law doctrine where the labours of married mothers in long-term marriages are recognised but only at the point of exit, namely, divorce. What is perplexing, however, is that, despite feminist critiques of mainstream economic theory and state policy, feminists' own conceptualisation of the production boundary is somewhat limited when it comes to reproductive labour. In the literature on social reproduction, the 'reproduction boundary', if we may call it that, is fairly consistently and strictly drawn around unpaid reproductive labour performed in a relational context or the reproductive labour of working mothers

24 Shamir (n 5) 431.

25 Ibid 435.

26 See, in particular, K Quinn, 'Mommy Dearest: The Focus on the Family in Legal Feminism' (2002) 37 Harvard Civil Rights-Civil Liberties Law Review 447.

27 A Barlow, 'Configuration(s) of Unpaid Caregiving within Current Legal Discourse in and around the Family' (2007) 58 Northern Ireland Legal Quarterly 251

28 See also S Wong, 'Would You “Care” to Share your Home?' (2007) 58 Northern Ireland Legal Quarterly 268 for how courts have adjudicated property claims when cohabitation arrangements end.

29 J Conaghan and E Grabham, 'Sexuality and the Citizen Carer' (2007) 58 Northern Ireland Legal Quarterly 325,340 .

30 See Hoskyns and Rai (n 2) and their description of the successful campaign in the 1980s to get trade in services included under the regulatory system of the General Agreement on Tariffs and Trade. Reference to the production boundary is in relation to the SNA, or System of National Accounts, used by the UN to map national economies in order to establish gross domestic product, to identify national and global trends and to make cross-national comparisons. 
who struggle to balance work and care responsibilities. ${ }^{31}$ Glaringly absent is an understanding of reproductive labour performed by women for the market in terms of social reproduction. Admittedly, feminists have expressed concerns about the exploitation that the commodification of women's reproductive labour might bring. Yet the widespread nature of such labour necessitates at the very least some feminist critique of whether the market values and compensates women's labour appropriately.

I attempt to build on existing feminist scholarship to expand the reproduction boundary and understand women's reproductive labour, whether performed for the family or the market, in terms of a continuum. This is because the lived experiences of women like the surrogate protagonist Aasia in Made in India suggest that connections between various sectors of reproductive labour have more in common than feminists are willing to concede. I hope eventually to offer a cross-sectoral comparison of the law's treatment of women's labour markets spanning the market-family continuum with market-based, paid-for sexual labour at one end (sex work, bar-dancing) and family-based, unpaid-for care work at the other, with paid domestic work and surrogacy in between. In this article, however, I will focus only on sectors at the market end of the spectrum. To the extent that terms in the social reproduction debates like 'care work', 'care-giving', 'familial care'32 and 'unpaid caregiving 33 assume underlying affective arrangements, I use the term reproductive labour instead to de-exceptionalise social reproduction performed in the market for a price. The term 'reproductive labour' leaves open the possibility that feminists recognise the labour that women perform in these sectors, even if they vehemently disagree with their characterisation as work. Finally, although the study is specifically of Indian law, I hope that it will bear resonance in other contexts.

Before I elaborate on the sectors themselves, I will briefly highlight the regulatory continuum of social reproduction, which ranges from international law to domestic law. This regulatory matrix influences the discursive fields of debate and the regulatory disposition of the state towards female labour markets, which in turn has implications for the mobilisational repertoires of reproductive labourers themselves and the venues in which they seek to intervene. Here, the resolutely international regulatory field in which legal feminists today operate is significant. Related to this salience of international law for feminist legal interventions is the emergence of governance feminism, ${ }^{34}$ which has been the most visible in the violence-against-women campaigns targeting sex work, trafficking and

31 Conaghan and Grabham (n 29) 326. There are exceptions. Conaghan and Grabham refer to the considerable economic and affective consequences for sexual minorities of the dominant construction of unpaid caregiving where the 'reality' of lesbian and gay relationships 'evidences a variety of configurations of intimacy, which include friends, lovers, former partners, "fuck buddies". However, this is rare and does not speak to market-based forms of reproductive labour. Ann Stewart is one of the few scholars who deploy development economics and specifically the notion of global care chains to discuss such market-based reproductive labour: see A Stewart, 'Who Do We Care About? Reflections on Gender Justice in a Global Market' (2007) 58 Northern Ireland Legal Quarterly 359; see also A Stewart, Gender, Law and Justice in a Global Market (CUP 2011).

32 Shamir (n 5).

33 This is the term that the special issue of the Northern Ireland Legal Quarterly 58(4) uses.

34 Halley defines governance feminism as: 'an under recognized but important fact of governance more generally in the early twenty-first century. I mean the term to refer to the incremental but by now quite noticeable installation of feminists and feminist ideas in actual legal-institutional power. It takes many forms, and some parts of feminism participate more effectively than others; some are not players at all. Feminists by no means have won everything they want - far from it - but neither are they helpless outsiders. Rather, as feminist legal activism comes of age, it accedes to a newly mature engagement with power.' J Halley, P Kotiswaran, H Shamir and C Thomas, 'From the International to the Local in Feminist Legal Responses to Rape, Prostitution/Sex Work, and Sex Trafficking: Four Studies in Contemporary Governance Feminism' (2006) 29 Harvard Journal of Law and Gender 335-423, 340. 
rape. Importantly, governance feminism is heavily invested in the use of criminal law to prohibit such 'violence', especially with respect to sex work. Governance feminists have also consistently opposed the characterisation of sex work, erotic dancing and commercial surrogacy as labour, preferring to view them as forms of unbridled violence against women. Hence, any effort to redraw the feminist reproduction boundary must acknowledge their growing influence. In relatively newer sectors of female reproductive labour such as transnational commercial surrogacy, meanwhile, conventional private international law rules are only beginning to assume significance as the domestic legal validity of foreign contracts for commercial surrogacy or the citizenship status of babies born out of such arrangements are litigated. Sectors such as bar-dancing and unpaid housework meanwhile tend to be regulated in more domestic, national legal terms.

\section{Sex work, bar-dancing and commercial surrogacy}

In the following section, I will elaborate on the law's appropriation of female reproductive labour across sectors involving sex work, bar-dancing and surrogacy. I will outline the default legal architecture in these sectors, the feminist discourse surrounding them, and how reproductive labourers themselves have responded. Further, the Indian state's differential treatment of these sectors despite their structural similarities highlights once again the contingency of the law's treatment of female reproductive labour. Feminists then need to grapple with whether an alternative regulatory matrix would further women's claims to economic justice and, if so, at what moments in time and under what conditions are shifts in the default legal categorisation possible? Before I set out to do so, I will refer to the scale of these sectors and the distinct time periods over which they developed. The Indian sex worker population is estimated to be between 1 and 2 million. The number of bar dancers, predominantly in the state of Maharashtra in 2006 before the sector was banned, stood at 75,000 . Despite the bullish persona that advocates of the surrogacy sector consistently portray in India and internationally, its exact scope is far from clear. Even the clinics with the largest surrogacy practice have only recently passed the 500 mark for a baby born out of a surrogacy arrangement. As such, the number of surrogates is likely to be only a few thousand. The scale of these sectors also reflects patterns of their growth. Sex work in its contemporary form has been in existence in India for at least two centuries if not longer, although shifts in its organisation and its quite distinct regional configuration are palpable. Bar-dancing emerged in the Western Indian state of Maharashtra in the 1980s, possibly in the wake of the deindustrialisation of Mumbai. Although the sector has been significantly scaled back in the state following a 2006 ban and pending its litigation in the Supreme Court of India, dance bars have sprung up elsewhere in the country. The surrogacy industry on the other hand is relatively new, having taken off only in the past 10 years, largely due to the increase in foreign commissioning parents. I now turn to each of these sectors in more depth.

\section{Sex work}

Of the three forms of reproductive labour that I consider, sex work is arguably the most stigmatised. Indeed, it is so stigmatised that feminists have disagreed for long over its very characterisation as a form of labour. Sex workers the world over, including in India, have, however, persisted in campaigning for an alternative characterisation of sex work as legitimate work. The Indian anti-sex work criminal law, the Immoral Traffic Prevention Act 1956 (ITPA), not unlike laws relating to sex work elsewhere in the world, does not criminalise the sale of sex per se but criminalises all activities that are required in order to perform sex work. The inherent ambiguity in the legislative framework, which tolerates individually negotiated, discrete sex work transactions but not commercialised sex work 
businesses that are publicly visible, results in the highly corrupt enforcement of the ITPA. Duncan Kennedy's concept of the tolerated residuum of abuse helps clarify the role of criminal laws such as the ITPA. Writing in the context of rape laws, Kennedy has proposed that the legal system will always tolerate a certain level of sexual abuse, which he termed the tolerated residuum of abuse. This tolerated residuum of abuse depends on contestable social decisions about what abuse is and how important it is to prevent it. This in turn affects practices of abuse and social practices of both men and women, irrespective of whether they themselves are abusers or victims. ${ }^{35}$ At times, the law may even generate violence against women as in the case of anti-sex work laws ${ }^{36}$ like the ITPA. The ITPA is used excessively to prosecute sex workers rather than other stakeholders in the sex industry. The Indian state also uses a range of other general criminal laws such as the Indian Penal Code 1860, local government laws and specialist anti-narcotics laws to harass sex workers. Since the crime statistics data do not record the extent of the use of these laws against sex workers, much less, the countless threats to invoke them against sex workers, the tolerated residuum of abuse against sex workers is in fact likely to be quite large. The state here directly appropriates the labour of sex workers through the rent-seeking behaviour of the police who collect bribes for withholding prosecution against them or by imposing fines upon conviction, which only translate into sex workers' need to perform additional sex work. The state also indirectly appropriates women's labour by deriving ideological benefits. Anti-sex-work laws not only successfully terrorise and sexualise sex workers, 37 but also, women and men who are only remotely connected to the sex industry, thus reiterating hegemonic gender identities.

Layered over these state practices, however, has been the consistent rise of feminist discourse within state expert bodies such as the National Commission for Women, which, in line with the predominant radical feminist take on sex work as nothing but violence against women, views Indian sex workers essentially as prostituted victims of patriarchy and poverty. Feminist abolitionist non-governmental organisations have popularised this stance while sex work remains largely ignored by the autonomous Indian women's movement. Meanwhile, the public health discourse, animating the state's large-scale HIV prevention efforts, views female sex workers as 'agents' who are necessary for HIV prevention efforts. Both these discourses have to some extent influenced the senior ranks of the police bureaucracy which may direct the lower ranks to desist from harassing sex workers thereby altering the tolerated residuum of abuse, although insignificantly. Moreover, since 2000, international trends on prostitution policy have undergone a significant change with the negotiation of the UN Protocol on Trafficking 38 and the passage of the US law, the Victims of Trafficking and Violence Protection Act 2000 (VTVPA), which ranks countries according to their efforts to prevent, prosecute and punish trafficking. States have also resorted to the Swedish model of criminalising customers of sex workers while decriminalising sex workers themselves. Indeed, this trend found expression in an amendment to the ITPA in 2006, which lapsed in Parliament in March 2009 due to a schism within the Indian Union Cabinet produced by the competing prerogatives of anti-trafficking discourse on the one hand and HIV prevention on the other. Following this defeat of the abolitionists, but anticipating legislative action in light of India's ratification of the UN Trafficking Protocol in June 2011,

35 D Kennedy, Sexy Dressing: Essays on the Power and Politics of Cultural Identity (Harvard University Press 1993), 137

36 Ibid.

37 M Frug, 'A Postmodern Feminist Legal Manifesto (An Unfinished Draft)' (1991-1992) 105 Harvard Law Review 1049-50.

38 A Protocol to Prevent, Suppress and Punish Trafficking in Persons, Especially Women and Children, supplementing the United Nations Convention Against Transnational Organized Crime GA Res 25, Annex II, UN GAOR, 55th Session, Supp No 49, at 60, UN Doc A/45/49 (vol I) (2001). 
sex workers' groups, which had since the early 1990s mobilised sex worker communities and shied away from formal legal venues for contesting, are now shifting their tactics. They recently launched a constitutional challenge to several sections of the ITPA almost five decades after it initially passed constitutional muster.

\section{Bar-dancing}

As is evident in the case of sex work, the default legal categorisation of women's reproductive labour raises the bar for its recategorisation through the efforts of feminists and sex workers alike. This is why the case of bar-dancing is instructive because feminists were able to reorient the state's disposition towards the regulation of bar-dancing. What made this legal recategorisation possible despite the structural similarities of bar-dancing and sex work and women's experience of them? Bar dancing as a sector grew in the Indian state of Maharashtra starting in the mid-1980s and by 2006, when it was banned, easily employed about 75,000 dancers and 800,000 men and women in related employment. The sector was regulated by an elaborate labyrinth of licensing regimes relating to food, liquor and public entertainment, as well as by the public nuisance provisions of the Bombay Police Act 1951 and s 294 of the Indian Penal Code 1860 relating to obscenity. A conservative provincial government took over and banned bar-dancing in bars other than those located in hotels with three stars or above. The justification was the negative externalities that such behaviour produced as well as the offence to the dignity of women. Bar owners challenged the ban and the Mumbai High Court overturned the ban, upholding the right to livelihood of bar dancers. ${ }^{39}$ The Indian Supreme Court recently upheld the Mumbai High Court's decision. I focus on the High Court's decision as it pertains more directly to my argument in this article.

The Mumbai High Court decision was clearly a cause for feminist celebration. The court, after all, demonstrated a keen awareness of the gender bias operative in the state's ban, was not convinced that bar-dancing was against the public interest, and held that women could not be effectively penalised for men's insatiable sexual needs ${ }^{40}$ or the public consequences of liquor consumption. ${ }^{41}$ It reminded the state that many of the bar dancers were widowed, deserted or divorced and trying to earn a decent living for themselves and their families. Even if some were exploited, the state could not prevent others from pursuing a livelihood of their choice, even if involuntary at times. The court also challenged the state's notion that bar dancers stay poor rather than engage in unpalatable work. Thus, judges asked why an illiterate but otherwise beautiful girl should be prohibited from earning well through dancing rather than be condemned to a life of menial jobs? ${ }^{42}$

At the same time, the court drew a bright line between bar-dancing and sex work. It held that dancing was not inherently pernicious and was therefore res commercium, unlike sex work which, being immoral, was res extra commercium, that is outside commerce. Dancing, the court noted, had an illustrious past since ancient Indian times, including in Maharashtra, ${ }^{43}$ so that, if bar-dancing was harmful, then, Bollywood dancing would have to be banned. Thus, we find the court reluctant to challenge more fundamentally the sharp distinctions drawn between sex work and bar-dancing. Interestingly, there are many structural similarities between sex work and bar-dancing in terms of the social origins of the dancers, their previous employment, such as domestic work, their self-understanding of their work as

39 Indian Hotel and Restaurants Association (IHRA) v State of Maharashtra (2006) 3 Bombay Cases Reporter 705.

40 IHRA 219.

$41 \operatorname{IHR} A 223$.

$42 \operatorname{IHR} A$ 222-3.

43 IHRA 191. 
dignified, the support systems they relied on, the spatial concentration of bar dancers' residences in red-light areas, the levels of social stigma they endured, the internalisation of this stigma, and the unlikeliness of marriage as an exit option. Significantly, the state's enforcement of laws governing bar-dancing was not unlike its enforcement of anti-sexwork criminal laws. Both sectors faced the threat of enforcement and the attendant harassment, which resulted in the payment of bribes or the public arrest and humiliation of sex workers and bar dancers. This in turn undermined women's bargaining power vis-à-vis other stakeholders in the industries.

Interestingly though, anti-ban feminists repeatedly insisted that dancing was anything but sex work, instead of challenging the more fundamental divide between moral and immoral women. Admittedly, they did so for strategic reasons as they had to urgently deal with the closure of dance bars and fight for bar dancers' rights. This strategic mode of legal arguments, however, invited legitimation in judicial discourse. The distancing of bardancing from sex work was achieved only through the normalisation of bar-dancing itself. Dancing by women has generally become more respectable given the popularity of Bollywood dancing amongst middle-class women in fitness clubs. ${ }^{44}$ Bar dancing was also thought to satisfy the legitimate male need for entertainment met previously by indigenous traditions of female dancing. Indeed, poor male migrants' rights to sexual entertainment were offered as resistance to globalisation.

Bar dancing was also justified in terms of women's livelihoods. The commodification anxiety of feminists from barely a decade ago, when they opposed women's beauty contests, was missing. Consequently, instead of abolition, feminists called for the increased regularisation of the working conditions of bar dancers. This is true even of radical feminist organisations like the Bangalore-based Vimochana, which has been vocally opposed to sex work but supports better working conditions for bar dancers. So, we have here an instance of legal mobilisation that forced feminists to draw lines between sectors in female reproductive labour, which in turn became consolidated in judicial discourse. Success in campaign terms can perhaps only be achieved by sacrificing discursive complexity. ${ }^{45}$ Yet, once we acknowledge the interconnectedness of the rule network governing women's reproductive labour, it follows that some reproductive labourers will likely bear the costs of the strategic successes of other reproductive labourers.

\section{Commercial surrogacy}

Commercial surrogacy offers yet another interesting case study for the Indian state's regulation of reproductive labour. Unlike with sex work and bar-dancing, where feminist abolitionists forcefully demand to be convinced of women's reproductive labour, no one, let alone a feminist, will deny the labour involved in reproducing babies. The question then is whether women should perform such labour for others and, if so, under what circumstances and whether it can legitimately be called work. Here, there are several discursive similarities between sex work, bar-dancing and commercial surrogacy. Thus, feminist objections to surrogacy on the grounds of objectification, exploitation, subordination, the domino effects of unrestricted commodification and the social and cultural hierarchies that it entrenches, and its bolstering of heteronormativity and the

44 A Morcom, Illicit Worlds of Indian Dance Cultures of Exclusion (C Hurst \& Co Publishers Ltd 2013).

45 See Frug's observations on feminist legal strategising around pornography where she notes how the feminist impulse to abolish pornography rather than deconstruct it limited the liberatory potential of the original feminist insight into female sexual subordination: Frug (n 37) 1073-4. 
patriarchal family form, all seem familiar. ${ }^{46}$ Indeed, the very same Western radical feminists who demanded the abolition of sex work also opposed commercial surrogacy early on, equating surrogacy hostels with brothels. ${ }^{47}$ It comes as no surprise then that an Indian male Marxist academic recently termed gestational surrogacy as 'reproductive trafficking' or 'consensual slavery'. ${ }^{48}$

Interestingly, Indian feminists have been reluctant to call for a ban on commercial surrogacy. ${ }^{49}$ Many feminists acknowledge that it is too late to ban gestational surrogacy; it is inevitable and here to stay. They instead express concern about the exploitation of surrogates. Others have clearly articulated their concern as to the domino effects of a market in commercial surrogacy driven by neoliberal capitalism. ${ }^{50}$ Their anxieties are exemplified by the 21-year-old surrogate featured in a TV show who does it to educate her daughter to become like the English-speaking Indian elite and has no reservations doing it again if 'she likes it'. When asked about whether poor women might not be exploited into becoming surrogates, she insists that she is not coerced; it is this expression of neoliberal subjectivity that worries many feminists. For the time being, however, the regulatory preoccupation for feminists pertains to surrogates' rights - the need for informed consent, the ambit of health insurance during surrogacy, how often they can be surrogates and so on. ${ }^{51}$

The substantial involvement of a professional group like the medical community in surrogacy sets it apart from sex work and bar-dancing, which are associated with so-called 'lumpen' elements in society. Not unsurprisingly, many doctors call for commercial surrogacy to be kept legal, with some catering quite consciously to foreign commissioning parents in riding the wave of increased medical tourism, which the Indian state has keenly promoted. Others estimate that 80 per cent of their patients are Indian couples and, in a country of India's size and social context, which stigmatises infertility, permitting surrogacy is the only rational thing to do. ${ }^{52}$ Online advertisements promoting commercial surrogacy meanwhile invoke the human right to reproduce and marry and promote India as a familyfriendly country where children born from surrogacy will be loved and not trafficked. Remarkably, the Indian surrogacy market is estimated to generate $\$ 2.3$ billion annually. ${ }^{53}$

The Indian state supports commercial surrogacy through the fairly permissive nonbinding guidelines of the Indian Council of Medical Research (ICMR) on Assisted Reproductive Technologies (ART). ${ }^{54}$ Under these guidelines, commercial surrogacy in India takes the form of gestational surrogacy whereby surrogates for a fee bear babies that are

46 R West, Caring for Justice (New York University Press 1997) 50-61; M Radin, Contested Commodities: The Trouble with Trade in Sex, Children, Body Parts, and Other Things (Harvard University Press 2001), 131-53, 154-63; V Marwah and N Sarojini, 'Reinventing Reproduction, Re-conceiving Challenges: An Examination of Assisted Reproductive Technologies in India' (2011) 46(43) Economic and Political Weekly 104-11.

47 J Raymond, Women as Wombs: Reproductive Technologies and the Battle over Women's Freedom (Spinifex Press 1993).

48 M Rao, 'Why All Non-Altruistic Surrogacy should be Banned' (2011) 47(21) Economic and Political Weekly 15-17.

49 Ibid 15

50 I Qadeer, New Reproductive Technologies and Health Care in Neo-Liberal India: Essays (New Delhi Centre for Women's Development Studies 2010).

51 Sama Team, 'Assisted Reproductive Technologies: For Whose Benefit' (2009) 44(18) Economic and Political Weekly 25-31.

52 India Decides, NDTV interview with Dr Kamini Rao, Assisted Conception Centre, Bangalore and Dr Rishikesh Pai, Mumbai Leelavati Hospital (December 2011).

53 S Lee, 'Commercial Surrogacy Grows in India' (SFGate 20 October 2012) <www.sfgate.com/health/article/Commercial-surrogacy-grows-in-India-3968312.php>.

54 National Guidelines for Accreditation, Supervision and Regulation of ART Clinics in India, Ministry of Health and Family Welfare, Government of India, Indian Council of Medical Research, 2005. 
genetically unrelated to them. In the shadow of these guidelines, the sector has developed internal social norms driven by the medical requirements for ensuring a successful 'outcome', namely, a live birth. Norm generation has also spilled over to aspects such as the issue of travel documents by Western embassies to enable foreign commissioning couples to take their babies home. As the sector expands and the stakes of the major fertility clinics grow, in order to alleviate the existing legal uncertainty around commercial surrogacy, they have called for the passage of a statutory law. Thus, the ICMR guidelines form the basis for the Assisted Reproductive Technologies (Regulation) Bill 2010 (ART Bill). ${ }^{55}$ This Bill is highly atypical when compared to laws in most other countries, which prohibit commercial surrogacy and allow altruistic surrogacy only under certain circumstances, if at all.

The proposed ART Bill when passed by the Indian Parliament will be one of the most liberal surrogacy laws in the world. Although the ART Bill is yet to be passed, its regulatory logic in relation to this sector of women's reproductive labour is revealing. The ART Bill envisages a vastly permissive zone within which parties to the surrogacy transaction contract subject to certain limits. These limits include, inter alia, restrictions on the age of the gamete donor and surrogate, the number of embryos that can be implanted in a treatment cycle, and the prohibition of a negotiating role for the ART clinic in arranging the surrogacy transaction. Many of these restrictions are already to be found under the ICMR guidelines but are rarely enforced by the state itself, with the police intervening only when a surrogate or egg donor dies. Contract is thus the overarching framework within which female reproductive labour is recognised and valued.

For a state that has sought to abolish market-based sectors in reproductive labour, such as sex work and bar-dancing, and embodies an ideology of gendered familialism in relation to child-care, its stance on commercial surrogacy is perplexing. Incomprehensibly, nationalist conservatives have not asked to date why Indian wives and mothers should carry babies for 'foreigners'. Those on the left have queried India's permissive stance given India's high maternal mortality rate and the poor state of medical care for women who reproduce for their own families. Some have pointed to how medical tourism amounts to a reverse subsidy to the elite. ${ }^{56}$ The only plausible explanation for the ART Bill is surrogacy's ultimate goal of procreation and its enhancement of the hetero-patriarchal family model. The subtext appears to be the promotion of a very specific form of market dealing in ART. Surprisingly, therefore, the Bill does not permit altruistic arrangements, such as the donation of sperm or oocyte by a relative or known friend of the parties seeking ART treatment. ${ }^{57}$ The ART Bill also does not permit the surrogate to contribute oocyte material to the baby, ${ }^{58}$ even when the commissioning mother cannot use her own egg, leaving the parents to source it independently. This in turn necessitates the intense fragmentation of reproductive raw materials enhancing the possibility of their commodification in the market. The property rights of marital parties to each other's reproductive materials are, however, protected as spousal consent to the ART procedure and to one's wife becoming a surrogate

55 Available at <http://icmr.nic.in/guide/ART\%20REGULATION\%20Draft\%20Bill1.pdf>.

56 A Sengupta, 'Medical Tourism: Reverse Subsidy for the Elite' (2011) 36 Signs: Journal of Women in Culture and Society 312-19; S Reddy and I Qadeer, 'Medical Tourism in India: Progress or Predicament?' (2010) 45(20) Economic and Political Weekly 69-75.

57 S 20(12); this is particularly odd in light of reports that 50 per cent of Indian egg donors and 25 per cent of surrogates are family members: R Sharma, 'Gene factor: Surrogacy stays within the great Indian family' (Bavishi Fertility Institute 9 January 2009) <http://www.ivfclinic.com/surrogacy_its_all_in_the_ family_for_indians.html>. Doctors whom I interviewed view this provision as essential to avoid intra-family disputes over property. 
is required. ${ }^{59}$ Thus, the marital family's rights over the wife's reproductive labour are always protected. In recognition of the surrogate's reproductive labour, the Bill states that the surrogacy contract is to be legally enforceable. ${ }^{60}$ In addition to medical and insurance expenses relating to the pregnancy, ${ }^{61}$ the surrogate may receive monetary compensation for her services. ${ }^{62}$ Upon the birth of the baby, however, she has to give up all parental rights ${ }^{63}$ and cannot keep the baby even if she changes her mind or if the commissioning parents change their mind. The commissioning parents meanwhile are required to accept the baby irrespective of abnormalities. Where unclaimed, the baby is to be put up for adoption. Thus, the rights of the commissioning parents over the product of the surrogate's labour are well protected while ensuring that the state has no responsibility towards the baby should the surrogacy arrangement fail.

In the Indian surrogacy market, the most successful fertility clinics recruit surrogates and gamete donors, perform the in-vitro fertilisation (IVF) procedures, operate a surrogacy hostel for surrogates, and finally deliver the babies, apart from informally facilitating travel, accommodation, and birth registration and visa formalities for foreign couples. In an attempt to diffuse the clinic's power, the ART Bill requires a functional separation between the ART clinic and ART bank such that, the ART Bank recruits gamete donors and surrogates while the ART clinic only performs the IVF procedures. Interestingly, the Bill prohibits the use of individual brokers and paid intermediaries, who might include the village midwife 64 (or even the local electrician), to obtain gamete donors and surrogates, making it punishable by imprisonment for three years and a fine. Thus, even in calling upon women to perform for the market, the state has a particular view of who its economic agents should be.

The ART Bill visualises multiple sets of contracts between the various parties based on the assumption that they are equally placed, free, rational agents acting with informed consent. In reality, surrogates and commissioning parents, especially foreign commissioning parents, are divided by huge disparities in power and social status. Informed consent largely appears to be a farce; 65 what drives the market is surrogates' need for money to meet the needs of their own families and children. Surrogates are likely to belong to disadvantaged sections in urban and semi-urban areas. ${ }^{66}$ In media appearances, many spoke Hindi and aspired to upper-class education and mobility. Surrogates' reproductive labour is not free of shame or stigma. Amrita Pande characterises commercial surrogacy in India as sexualised care work incorporating aspects of both sex work and care work. ${ }^{67}$ Confirming this is the common veiling of surrogates in the media. Stigma, according to Pande, undermines the formation of worker identity while the surrogate-sex worker comparison is constantly

59 S 34(16).

60 S 34(1).

61 S 34(24).

62 S 34(3).

63 S 34(4).

64 A Pande, “'At least I am not sleeping with anyone”: Resisting the Stigma of Commercial Surrogacy in India' (2010) 36 Feminist Studies, Special Issue: Reproduction and Mothering 292-312; A Pande, 'Commercial Surrogacy in India: Manufacturing a Perfect "Mother-Worker" (2010) 35 Signs: Journal of Women in Culture and Society 969-92; A Pande, 'Not an "Angel", Not a "Whore": Surrogates as "Dirty" Workers in India' (2009) 16 Indian Journal of Gender Studies 141-73.

65 S Saravanan, 'Transnational Surrogacy and Objectification of Gestational Mothers' (2010) 45(16) Economic and Political Weekly 26-9, 27.

66 S Banerjee, 'The Curious Case of Commercial Surrogacy' (Countercurrents.org 9 March 2011) $<$ www.countercurrents.org/banerjee090311.htm>.

67 Pande, 'Commercial Surrogacy', 'Not an "Angel”, Not a "Whore”' (n 64). 
deployed at different stages of the labour process to both legitimise surrogacy but also to discipline the surrogate. Surrogacy's similarity with care work meanwhile demands the surrogate be a good biological mother, but within limits lest she gets too attached to the baby and refuses to hand it over to the commissioning parents. So far, the prospects for the mobilisation of surrogates have been limited. Yet, the fact that most large infertility clinics require that their surrogates spend a large part of their pregnancy in clinic-run surrogate hostels offers some possibility for collective action, even if limited by the clinic's surveillance of these women.

\section{Modes of the law's appropriation of women's reproductive labour}

I have so far examined three market-based sectors of female reproductive labour. Formally speaking, they are governed by three different areas of the law: sex work through criminal law; bar-dancing through licensing law; and surrogacy through contract law. Substantively, the default position in the sex-work and bar-dancing sectors has been to allow for a highly circumscribed zone of permission overlaid with a prohibitionist regime enforced through criminal law. By contrast, the ART Bill facilitates contracts between the various parties to a surrogacy transaction within specified limits. There are, however, several structural similarities in the political economies of these sectors, and a deep interconnectedness in the way that women experience these labour forms.

Revealing the law's contingency helps us ask if and how an alternate legal treatment of women's labour may enhance their bargaining power. In other words, what if surrogacy was to be regulated by labour law instead of contract law or if housewives were paid wages or the state ran brothels. More significantly, it reminds us that, in feminist attempts to redraw the reproduction boundary, rule changes in any given sector of reproductive labour invariably have repercussions for women in related sectors. Thus, it should not be surprising that the legal status of bar-dancing turned on what the Mumbai High Court thought of sex work in normative and legal terms. Similarly, it should not be surprising that the surrogacy industry touts the homely and docile nature of Indian surrogates in an international marketplace while comparing surrogates to sex workers to discipline them. Reminders of this interconnectedness at least with the marital economy are evident in the ICMR guidelines, which are replete with references to the legitimacy of the baby born of a surrogacy agreement, the non-adulterous nature of ART when performed with the husband's consent, and conception through ART not precluding marital dissolution on the basis of impotency and so on. ${ }^{68}$ After all, Mary Joe Frug reminded us several years ago that different sets of legal rules and the meaning of the female body are intertwined as they set about permitting and mandating the terrorisation, maternalisation and sexualisation of the female body. ${ }^{69}$ Thus, just as anti-prostitution rules terrorise and sexualise sex workers, but also maternalise them, so also, the ART Bill both maternalises and sexualises the female body. The legal rule networks regulating the varied sectors of women's reproductive labour are thus profoundly interrelated and affect not only women's bodies in that sector but in other sectors as well.

The push to assess the distributive impact of rules across sectors is not a purely theoretical exercise either. Based on my empirical research on sex work in India, I have offered three ways of conceptualising the relationship between sex work and marriage. The two institutions overlap, as evidenced by the housewife-sex worker; they occupy a continum; which explains the high percentage of ex-wives amongst sex workers and the bargains that

68 ICMR guidelines (n 55) 3.16 of ch 3.

69 Frug (n 37) 1049-50. 
wives and whores strike with each other, images of which popular culture is replete with. ${ }^{70}$ A similar analysis could be extended to the bar-dancing and surrogacy sectors such that housewives, sex workers, bar dancers and surrogates are viewed at times as participating in more than one sector of social reproduction at once (as in commercial surrogacy), at times moving between these sectors, while also often developing conflicting interests towards each other. Given this complex relationship between sectors of reproductive labour, changes in rules affect the choice (relatively speaking) of women like Aasia - should she remain a housewife, do domestic work in others' homes, become a surrogate, join a dance bar or perform sex work on an ad hoc basis? ${ }^{71}$

An initial provocation for my article was to query why certain forms of reproductive labour were prohibited while others were permitted. At the outset, it appears that the laws regulating social reproduction even within a certain sector can be rife with contradictions. ${ }^{72}$ If, however, one were to persist in explaining the paradoxical regulation of social reproduction across sectors, another line of critique is plausible, one which attributes the law's dual regulation of women's bodies to the forces of capital, both in the post-industrial West and in the global South. Linda Singer, for instance, convincingly argues that late capitalism disciplines as well as mobilises sexuality. Hence, its oppositional logic maintains sex for money as a distinct segment while uncompensated sexual exchanges are hegemonised and naturalised to sustain dominant class and gender interests. ${ }^{73}$ The postcolonial variant of this argument is that, in a representative democracy, development discourse and welfarist governmentality ${ }^{74}$ mediate the relationship between the formal (corporate) and informal (non-corporate) sectors to ensure hegemony. ${ }^{75}$ Capital flows from the capitalist space to the developmental state to accommodate the castaways of capital's agenda in pre-capitalist sectors. Even as these scholars view the household as performing for capital, an empirical view of any of the markets I have considered would convincingly show how they they can hardly be said to contribute to the logic of capital. As such, they only incidentally benefit from favourable govermentsal categorization.

\section{The market demands rights}

The theories of capital above are somewhat inadequate to account for the regulatory paradoxes of social reproduction. Yet, they do offer a backdrop against which to think through the transformation of markets in female reproductive labour without rehearsing irrational fears of the market, overstating causal arguments as to the role of capital or abstract concepts such as exploitation, coercion and subordination. An aspect of this

70 P Kotiswaran, 'Wives and Whores: Prospects for a Feminist Theory of Redistribution' in C Stychin and V Munro (eds), Sexuality and the Law: Feminist Engagements (Routledge-Cavendish 2007) 283-302.

71 I acknowledge here that this might be particularly relevant in the Indian context where the rate of marriage is near universal: Palriwala and Neetha (n 10) 1068.

72 Note Shamir's assessment of the US Family Leave and Medical Act 1993 as 'ideologically Janus-faced' with the liberal face striving to achieve gender equality, through women's market participation and relaxed familial dependency, and the conservative face working towards women's familialisation and gender and class stratification: Shamir (n 5) 439. In the context of sex work, Western post-industrial cities increasingly criminalise sex work performed outdoors to create shiny, new redeveloped city centres while normalising sex work performed indoors where it can be safely consumed by the middle-classes: E Bernstein, Temporarily Yours: Intimacy, Authenticity, and the Commerce of Sex (Chicago University Press 2007).

73 L Singer, 'Sex and the Logic of Late Capitalism' in J Butler and M MacGrogan (eds), Erotic Welfare: Sexual Theory and Politics in the Age of Epidemic (Routledge 1993) 49.

74 K Sanyal, Rethinking Capitalist Development: Primitive Accumulation, Governmentality and Post-Colonial Capitalism (Routledge 2007) 60.

75 P Chatterjee, 'Democracy and Economic Transformation in India' (2008) 43(16) Economic and Political Weekly 53-62, 58. 
neoliberal backdrop is the emergence of rights discourse. Acknowledging the rights of reproductive labourers to perform highly stigmatised work for the market may itself be viewed as symptomatic of these neoliberal shifts. However, I focus here on the rights of consumers. This was particularly salient in the bar-dancing case. The right to livelihood of bar dancers triumphed in part because it catered to the right to entertainment of male migrant workers in the city. The ART Bill similarly offers extraordinary protection of the right to reproduce. ${ }^{76}$ Facilitating the right of commissioning couples to reproduce aligns with the Indian state's ideology of gendered familialism. The ART Bill meanwhile maintains the hetero-patriarchal deal at the surrogate's end of the transaction as well. This is consistent with the state's own involvement through decades of population control planning with the management of women's reproductive abilities. Indeed, the Indian state developed ART as a way to reverse its population control strategies. ${ }^{77}$ Given the economic rewards of reproductive tourism, the state has not hesitated to front a liberal surrogacy law to incentivise the development of a market for which its reproductive labourers perform. This also allows the families of surrogates the kind of class mobility that the state's own weak redistributive efforts can hardly ensure. This is appropriation par excellence.

The rights of consumers are not unrestrained, however, as is evident in the context of sex work. There, channelling the international policy trend towards criminalising the demand for sex work, India proposed an amendment to the ITPA in 2006, which sought to punish customers of sex workers. The very same minister who proposed this amendment, however, offered a very different view of the demand for surrogacy. In a TV show on surrogacy, she supported legalising commercial surrogacy. Her argument was partpragmatic (that a ban against commercial surrogacy would be ineffective), part-ideological (that infertility is a cruel joke). Yet it was the pull of consumerism dressed up as scientific fortitude that seemed most convincing when she asked on behalf of commissioning mothers: 'If women can use frozen peas, why not frozen gametes?'

\section{Conclusion}

Social reproduction has been an issue of considerable significance for feminist scholars and lawyers alike for several decades now. Even as feminists need to continue to lobby states and international organisations to redraw the production boundary so as to acknowledge and value the unpaid reproductive labour of women, I argue that feminists also need to question our own reproduction boundary. The collective feminist psyche on social reproduction has so far been tethered to the unpaid reproductive labour that wives and mothers perform, either along with or without paid work in the market, extending at best to paid domestic workers who assist in delivering the reproductive labour commitments of the household. I suggest instead that we query feminist reluctance to consider as work the reproductive labour of women performed outside the confines of affective relational networks and for the market in locations such as the brothel, surrogacy hostel, dance bar or the nursing home. Viewing reproductive labour along a continuum facilitates a cross-sectoral comparison of the regulation of these sectors, which is on the verge of being a zero-sum game.

Feminist lawyers have rendered visible the contingency of legal categories in the regulation of social reproduction. While this offers alluring possibilities for legal reform, feminists cannot feel over-invested in shifting legal categories, as these are likely to produce

76 There are parallels here to the argument that Conaghan and Grabham make about gays and lesbians being reconfigured as 'citizen-carers' as a response to the care deficit and welfare state retrenchment rather than due to the success of liberal egalitarian strategies: Conaghan and Grabham (n 29) 333.

77 ICMR guidelines (n 55) 5. 
costs for other sectors of reproductive labour. The bar-dancing case is an example of such an illusory opportunity for transformation. Yet, as is evident in the struggles of sex workers, default legal categorisations remain significant; they 'stick' and determine the venues for mobilisation. Although a retreat from the criminal law seems necessary for criminalised sectors of women's labour, where the state harbours a large tolerated residuum of abuse, the realm of contract hardly suffices for ensuring that women perform reproductive labour for the market on their own terms. Drawing on the insights of feminist legal realism thus helps us assess more carefully the 'laws of social reproduction'. 
